See Article page 381.

\section{Commentary: Veno-venous extracorporeal membrane oxygenation in areas with high coronavirus disease 2019 (COVID-19) burden: Other causes must still be ruled out}

Dimitri Kalavrouziotis, MD, FRCSC, and Siamak Mohammadi, MD, FRCSC

The cardiac surgical community's attention has been highly focused, and rightly so, on the coronavirus disease 2019 (COVID-19) pandemic crisis for the past few months. Our extracorporeal membrane oxygenation (ECMO) expertise has been mobilized to address the patients with the most severe forms of respiratory failure secondary to COVID-19. ${ }^{1}$ The clinical picture of severe acute respiratory distress syndrome coronavirus 2 (SARS-CoV-2) infection is deceptively similar to many other known, and some less well described, causes of acute lung injury (ALI). ${ }^{2}$

In this issue of the Journal, Hayanga and colleagues ${ }^{3}$ reported a complex case of ALI during the early phase of the COVID-19 pandemic. A 30-year-old woman at 33 weeks of gestation, with a high index of suspicion for SARS-CoV2 infection, presented with a rapidly progressive severe hypoxic ALI refractory to maximal therapy. After failed traditional treatment maneuvers, the patient underwent veno-venous ECMO and immediate safe delivery of the fetus by cesarean delivery. The patient had a history of direct contact with individuals who were positive for SARS-CoV-2, and a radiologic pattern on thoracic

\footnotetext{
From the Department of Cardiac Surgery, Quebec Heart and Lung Institute, Quebec City, Quebec, Canada.

Disclosures: The authors reported no conflicts of interest.

The Journal policy requires editors and reviewers to disclose conflicts of interest and to decline handling or reviewing manuscripts for which they may have a conflict of interest. The editors and reviewers of this article have no conflicts of interest.

Received for publication July 3, 2020; revisions received July 3, 2020; accepted for publication July 7, 2020; available ahead of print July 11, 2020.

Address for reprints: Siamak Mohammadi, MD, FRCSC, Department of Cardiac Surgery, Quebec Heart and Lung Institute, 2725 chemin Sainte-Foy, Quebec City, Quebec, Canada, G1V 4G5 (E-mail: siamak.mohammadi@fmed.ulaval.ca).

JTCVS Techniques 2020;3:387

2666-2507

Copyright (C) 2020 The Authors. Published by Elsevier Inc. on behalf of The American Association for Thoracic Surgery. This is an open access article under the CC BY-NCND license (http://creativecommons.org/licenses/by-nc-nd/4.0/).

https://doi.org/10.1016/j.xjtc.2020.07.006
}

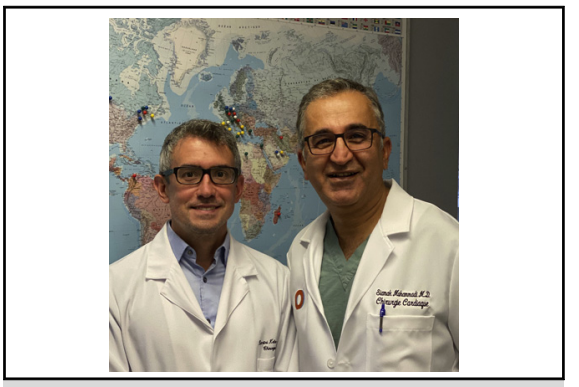

Dimitri Kalavrouziotis, MD, FRCSC, and Siamak Mohammadi, MD, FRCSC

CENTRAL MESSAGE

Even in patients with a high probability of exposure to SARSCoV-2, one must be vigilant for other causes of respiratory failure requiring veno-venous ECMO.

computed tomography highly suggestive of COVID-19. However, testing for COVID-19, as well as other microbiologic and viral pathogens, was negative, and further investigation revealed that she had been an active "vaper" up to her hospitalization. The patient ultimately did well; ECMO was weaned and the patient was discharged from hospital without complication.

Amid the new "clinical normal" imposed by the COVID19 pandemic, the case report by Hayanga and colleagues ${ }^{3}$ illustrates that cardiac surgeons, who remain the gatekeepers of mechanical circulatory support in most hospital systems, must remain sensitive to the panoply of causes of severe respiratory failure requiring veno-venous ECMO. An emerging indication, unfortunately obscured by the overwhelming global catastrophe of COVID-19, is vaping and e-cigarette-induced ALI, and must be evaluated in the differential diagnosis of severe refractory respiratory failure, even in patients with a high probability of exposure to SARS-CoV-2.

\section{References}

1. Shekar K, Badulak J, Peek G, Boeken U, Dalton HJ, Arora L, et al. Extracorporeal life support organization coronavirus disease 2019 interim guidelines: a consensus document from an international group of interdisciplinary extracorporeal membrane oxygenation providers. ASAIO J. 2020;66:707-21.

2. Sun Z, Zhang N, Li Y, Xu X. A systematic review of chest imaging findings in COVID-19. Quant Imaging Med Surg. 2020;10:1058-79.

3. Hayanga JWA, Hayanga HK, Dhamija A, Fugett J, Cook C, Powell D, et al Extracorporeal support to treat E-cigarette or vaping product use-associated lung injury (EVALI) during the coronavirus disease 2019 (COVID-19) pandemic. J Thorac Cardiovasc Surg Tech. 2020;3:381-4. 